\title{
Compaction and tableting properties of composite particles of microcrystalline cellulose and crospovidone engineered for direct compression
}

\author{
Fatima Haruna ${ }^{1}$, Yonni Eshovo Apeji ${ }^{1 *}$ (D, Chinyere Oparaeche ${ }^{2}$, Avosuahi Rukayat Oyi ${ }^{1}$ and Michael Gamlen ${ }^{2}$
}

\begin{abstract}
Background: Excipients with improved functionality have continued to be developed by the particle engineering strategy of co-processing. The aim of this study was to evaluate the compaction and tableting properties of composite particles of microcrystalline cellulose (MCC) and crospovidone (CPV) engineered by co-processing.

Results: Heckel analysis of the compaction behavior revealed a decrease in plasticity of co-processed excipient (CPE) when compared to MCC due to an increase in Heckel yield pressure from 144 to $172 \mathrm{MPa}$. The compressibility-tabletability-compactibility (CTC) profile revealed a decrease in individual parameters for CPE when compared to MCC. CPE was found to be more sensitive to the lubricant effect of sodium stearyl fumarate (SSF) when compared to MCC and less sensitive to magnesium stearate (MST) when compared to MCC. A higher dilution potential was obtained for MCC (60\%) compared to 44\% for CPE when metronidazole was used as model drug. Tableting properties revealed that metronidazole tablets generated with CPE by direct compression disintegrated within 15 min and gave a rapid drug release when compared to MCC as a direct compression (DC) excipient.

Conclusion: The compaction and tableting properties of CPE were characterized and yielded tablets with better disintegration and drug release profile when compared to MCC. This study, therefore, confirms the suitability of co-processing as a proven strategy in engineering the performance of excipients.
\end{abstract}

Keywords: Particle engineering, Microcrystalline cellulose, Crospovidone, Compaction studies, Tablet

\section{Background}

The development of novel excipients by co-processing has witnessed a surge in the last few decades. Coprocessing as a particle engineering technique has proven to be a useful strategy in improving the functionality or performance of existing single component excipients like lactose [1], microcrystalline cellulose [2], and starch $[3,4]$. Some of the functionality improvements so far recorded with co-processed excipients include enhanced flowability, compressibility, dilution potential, lubricant

\footnotetext{
* Correspondence: yehonathanapeji@gmail.com

1 Department of Pharmaceutics and Industrial Pharmacy, Faculty of

Pharmaceutical Sciences, Ahmadu Bello University, Zaria, Nigeria

Full list of author information is available at the end of the article
}

sensitivity, stability, moisture sensitivity, superdisintegrating ability, etc. These changes have been ascribed to physical modifications in the particle structure of excipients without recourse to their chemical properties. Hence, changes in the functionality of the developed co-processed excipients have been directly linked to changes in their fundamental properties like particle size, shape, and morphology [5]. Many of the co-processed excipients developed so far were designed for use as multifunctional excipients in direct compression formulations because of the growing preference for direct compression as the method of tablet production [6]. An ideal direct compression excipient should be multifunctional in performance, demonstrating sufficient flowability and compressibility as 
they constitute more than $50 \%$ of the tablet formulation and so determine to a large extent the outcome of the formulation. Hence, co-processed excipients designed for direct compression play a crucial role in tablet formation. The method of direct compression involves a two-step process of blending the formulation ingredients and compressing into tablets at suitable compression pressure. It is therefore necessary to evaluate the compaction behavior of co-processed excipients because the compaction behavior determines the tabletability or manufacturability of the formulation [7]. Compaction behavior refers to the mechanical response of a powder to the applied pressure [8]. During compaction, pressure is applied to transform the powder bed into solid compacts of suitable mechanical strength. This is a necessary step in the tablet-making process. Tableting materials under pressure may exhibit the mechanism of plastic deformation, elastic deformation, or fragmentation depending on the particle structure and chemical composition of the material [9]. Materials undergoing plastic deformation promotes the formation of tablets because they increase the bonding area between particles (compressibility) and bonding strength (compactibility) resulting in improved tabletability [10]. Hence, the present study aims to evaluate the compaction and tableting properties of the composite particles of MCC and CPV designed for use as a coprocessed multifunctional excipient in direct compression formulations. Compaction behavior of the co-processed excipient will be characterized using the conventional methods of Heckel and Kawakita analysis. In addition, compressibility-tabletability-compactibility (CTC) profile of the co-processed excipient in comparison to the constituent excipients, MCC, and CPV, will be generated with data obtained from compaction studies. Tablets containing metronidazole as the model drug will be formulated by direct compression. Dilution potential studies will be carried out to determine the drug-loading capacity of the excipient that will yield tablets of sufficient mechanical strength. To the best of our literature review, no such study has been carried out.

\section{Methods}

\section{Materials}

The following materials were used for the study: metronidazole (MTZ) (Central Drug House (P) Ltd. New Delhi, India), microcrystalline cellulose (MCC), Prosolv ${ }^{\circ}$ (PSV), crospovidone (CPV), sodium stearyl fumarate (SSF) (JRS Pharma, Germany), paracetamol (PCM), xylene, magnesium stearate (MST) (BDH Chemicals Ltd Poole, England), and colloidal silicon dioxide (Evonik Industries, Germany).

\section{Preparation of co-processed excipient (CPE)}

The co-processed excipient (CPE) was prepared by wet massing technique as described by Goyanes et al. [11] with slight modifications. The quantities of microcrystalline cellulose (MCC) and crospovidone (CPV) were calculated based on the optimized ratio, weighed out on an electronic balance (Mettler, Philip Harris Ltd, England) and pre-mixed for 5 min using a mortar and pestle. The powder blend was further massed with $20 \mathrm{~mL}$ of distilled water and the wet mass screened through a $0.5 \mathrm{~mm}$ sieve to achieve uniformity in particle size. The coprocessed material was then allowed to dry in an oven (Gallenkamp Oven BS size 3, England) at $40{ }^{\circ} \mathrm{C}$ for $1 \mathrm{~h}$ and kept in an airtight container for further studies.

\section{True density}

True densities of MCC, CPV, and CPE were determined using the liquid displacement method as described by Olayemi et al. [12] with slight modification. The empty weight of a pycnometer (density) bottle was obtained, filled with xylene, and its weight determined. A sample of the powder weighing $2 \mathrm{~g}$ was added into the bottle and the excess liquid spilled wiped off. The new weight was determined, and Eq. 1 below was used to calculate true density of the material having obtained the weight of xylene displaced by the sample.

$$
\rho_{T}=\frac{\text { weight of sample } \times \rho \text { of xylene }(0.864)}{\text { weight of xylene displaced by sample }}
$$

\section{Compaction studies}

Compaction profiles of $\mathrm{MCC}, \mathrm{CPV}$, and $\mathrm{CPE}$ were generated using the Powder Compaction Analyser (PCA028-1208, London, UK). Each tablet was prepared by manual filling of powder weighing $\sim 80 \mathrm{mg}$ into the die cavity measuring $5 \mathrm{~mm}$ and compressed at a speed of $120 \mathrm{~mm} / \mathrm{min}$ at compression loads ranging from 100 to $500 \mathrm{~kg}(50-250 \mathrm{MPa})$. For each pressure, a minimum of five tablets were compressed for reproducibility [13]. The parameters of weight, thickness, and hardness of tablets were measured using a balance (UWE serial no 136271/05), Micrometer (Mitutoyo Tokyo, Japan), and Tablet Tensile Analyser (TTA 331-1750, London, UK), respectively, and used to compute the volume [4], apparent density [14], and relative density (D) [15] of the tablets from the equations below:

$$
\begin{aligned}
& \text { Volume }(V)=\pi r^{2} h \\
& \text { Apparent density }\left(\rho_{A}\right)=\frac{\text { weight of tablet }(w)}{\text { Volume }\left(\pi r^{2} h\right)} \\
& \text { Rel.density }(D)=\frac{\rho_{A}}{\rho_{T}}
\end{aligned}
$$

where $r$ is the radius of the tablet and $h$ is the thickness of the tablet 
The compaction data obtained was used to generate Heckel [16], Kawakita [17], compressibility, compactibility, and tabletability plots for each material.

$$
\text { Heckel equation, } \ln \left(\frac{1}{1-D}\right)=K P+\mathrm{A}
$$

where $D$ is the relative density of the compact, $P$ is the applied pressure, the constant $K$ is a measure of the plasticity of a compressed material, and constant $A$ is related to the die filling and particle rearrangement before deformation and bonding of the discrete particles.

$$
\text { Kawakita equation, } \frac{P}{C}=\frac{P}{a}+\frac{1}{a b}
$$

where $P$ is the applied pressure, $C$ is the degree of volume reduction, parameters " $a$ " and " $b$ " are constants relating to the total degree of powder volume reduction and the yield strength of particles, respectively.

\section{Lubricant sensitivity ratio (LSR)}

The sensitivity of MCC and CPE to the effect of lubricant was evaluated by preparing tablets with or without MST/SSF using a Single Punch Tablet Press. Lubricant sensitivity ratio [18] was computed using the equation below

$$
\mathrm{LSR}=\frac{T_{o}-T_{L}}{T_{o}} \times 100 \%
$$

Where $T_{0}=$ tensile strength without lubricant, $T_{\mathrm{L}}=$ tensile strength with lubricant.

\section{Dilution potential}

Dilution potential of MCC and CPE was determined by preparing tablets of different formulations containing increasing concentration of the active pharmaceutical ingredient (MTZ/PCM) in the following ratios: 20:80, 40: 60, 50:50, 60:40, and 80:20 [2]). Tablets were prepared for each compression blend by direct compression on a Single Punch Tablet Press and tensile strength of tablets determined after $24 \mathrm{~h}$ of elastic recovery. A graph of \% drug composition against tensile strength was drawn, and the dilution potential of each material was extrapolated from the plot.

\section{Tableting}

Four formulations of tablets containing MTZ as the model drug were prepared by direct compression according to the formula given in Table 1 . Tablets weighing $~ 500 \mathrm{mg}$ were compressed on a Single Punch Tablet Press (Type EKO, Erweka, Apparatebau-G.m.b.H, Germany) using $12 \mathrm{~mm}$ flat-faced punches compressed at a load of $7 \mathrm{KN}$. The processed tablets were kept for $24 \mathrm{~h}$ and evaluated for its physical properties.
Table 1 Formula for preparing tablets containing metronidazole as model drug using MCC, CPE, PME, and PSV as DC excipients

\begin{tabular}{lllll}
\hline & \multicolumn{4}{l}{ Formulations } \\
\cline { 2 - 5 } Ingredients & I & II & III & IV \\
\hline MTZ (40\%) & 200 & 200 & 200 & 200 \\
MCC (59\%) & 295 & - & - & - \\
CPE (59\%) & - & 295 & - & - \\
PME (59\%) & - & - & 295 & - \\
PSV (59\%) & - & - & - & 295 \\
SSF (1\%) & 5 & 5 & 5 & 5 \\
Total (mg) & 500 & 500 & 500 & 500 \\
\hline I MCC as DC excipient, II CPE as DC excipient, III PME as DC excipient, IV PSV
\end{tabular}

as DC excipient

\section{Evaluation of tablet properties}

Physical properties of tablets prepared for each formulation were evaluated according to BP requirements [19]. The weights of 20 tablets picked at random from each formulation were obtained, and the mean and standard deviations were calculated to ascertain uniformity in weight of tablets for each formulation.

The thickness and crushing strength of 10 randomly sampled tablets from each formulation was measured using the Digital Vernier Calliper and Monsanto Hardness Tester, respectively. The mean and standard deviation for each parameter was recorded. The corresponding tensile strength (TS) was calculated for each formulation using the Fell and Newton equation [20] given below:

$$
T s=\frac{2 F}{\pi d t}
$$

where $F$ is the crushing strength, and $d$ and $t$ are the diameter and thickness, respectively.

Ten tablets from each formulation were randomly selected, accurately weighed, placed in the chamber of Digital Friability Test Apparatus 903 (Environmental \& Scientific Instruments CO., India), and allowed to rotate at $25 \mathrm{rpm}$ for $4 \mathrm{~min}$. Tablets were removed from the chamber, gently cleaned from dust particles, and accurately weighed. Friability was calculated in terms of percentage weight loss using Eq. 9:

$$
\text { Weight loss }(\%)=\frac{W_{i}-W_{f}}{W_{i}} \times 100 \%
$$

where, $w_{i}$ and $w_{f}$ are the weights of the tablets before and after friability test, respectively.

The time taken for six tablets from each formulation to disintegrate was determined using the BJ-3 Disintegration Tester (Ningbo Hinotek Instrument Co., Ltd, China). The experiment was conducted in a controlled temperature environment of $37 \pm 0.5^{\circ} \mathrm{C}$ using distilled water as the medium for disintegration. The mean and 
standard deviation of six replicates were computed and recorded for each formulation.

In vitro dissolution studies were carried out on the four formulations using $0.1 \mathrm{~N} \mathrm{HCl}$ as dissolution medium. A single tablet was placed in a beaker containing $900 \mathrm{~mL}$ of $0.1 \mathrm{~N} \mathrm{HCl}$ set at $37{ }^{\circ} \mathrm{C}$ and allowed to rotate at $100 \mathrm{rpm}$. Five milliliters of samples was withdrawn at 5, $10,20,30,45$, and $60 \mathrm{~min}$, respectively, and replaced with equal volume of $0.1 \mathrm{~N} \mathrm{HCl}$ after each withdrawal. The samples collected were filtered and sufficiently diluted with $0.1 \mathrm{~N} \mathrm{HCl}$ before taking the absorbance readings at $277 \mathrm{~nm}$ using the UV spectrophotometer (UV-1800 Spectrophotometer, Shimadzu Corporation, USA). The amount of drug released (\%) was calculated based on the equation, $y=0.0395 x+0.1314$, derived from the calibration curve of metronidazole and a plot of \% drug released against time was generated for the four formulations.

\section{Statistical analysis}

Data analysis was carried out in Microsoft Excel using the analytical tool $A N O V A$; single factor to evaluate the differences in tableting properties across the formulations. Differences in tableting properties were considered significant at $p \leq 0.05$.

\section{Results}

\section{True density}

A mean value of $1.48 \mathrm{~g} / \mathrm{mL}$ was obtained as true density for both MCC and CPE in comparison to a lower value obtained for CPV $(1.23 \mathrm{~g} / \mathrm{mL})$. This implies that coprocessing did not significantly affect the true density of MCC.

\section{Compaction studies}

Heckel and Kawakita plots presenting the compaction profiles of MCC, CPV, and CPE are displayed in Fig. 1. The Heckel plot (Fig. 1a) shows that the degree of densification (1/1-D) increases as the compaction pressure increases while the extent of volume reduction $(\mathrm{P} / \mathrm{C})$ increased with increase in compaction pressure as seen in the Kawakita plot (Fig. 1b).

The compaction parameters resolved from both plots are summarized in Table 2. Mean yield pressure, a Heckel parameter, which measures the degree of plasticity in a material was ranked in the following order, $\mathrm{MCC}<\mathrm{CPE}<\mathrm{CPV}$ implying that $\mathrm{MCC}$ had the least value of $144.93 \mathrm{MPa}$ corresponding to a greater degree of plasticity. The $D_{A}$ values representing the total degree of densification occurring at the initial stages of compression was relatively the same for MCC and CPE but differed significantly from that of CPV. Densification occurring as a result of particle slippage and rearrangement was quantified using $D_{O}$ parameter, and the values obtained for MCC and $\mathrm{CPE}$ were similar compared to that of CPV which was relatively higher (0.49) implying that the extent of densification occurring as a result of particle slippage and rearrangement was higher with CPV compared to the other two materials. The $D_{B}$ parameter representing the degree of densification occurring as a result of particle fragmentation was relatively similar for MCC and CPE and higher when compared to CPV.

The Kawakita parameters shows that the degree of compressibility for all three materials represented by " $a$ " was found to be similar. However, the compression effort $\left(P_{K}\right)$ required to achieve a $50 \%$ reduction in the volume of the powder bed during compression was found to be much lower for both MCC and CPE in comparison to $\mathrm{CPV}$ implying a greater degree of plasticity.

The CTC profile of MCC, CPV, and CPE is presented in Fig. 2. The compressibility plot denoted in Fig. 2a shows the effect of compaction pressure on the porosity of compacts. There was a decline in porosity of compacts as the applied pressure increased for all three materials. The extent of reduction in porosity was higher in MCC and CPE compared to CPV. The plot shows that the level of porosity reduction seen in MCC and CPE compacts was relatively the same.
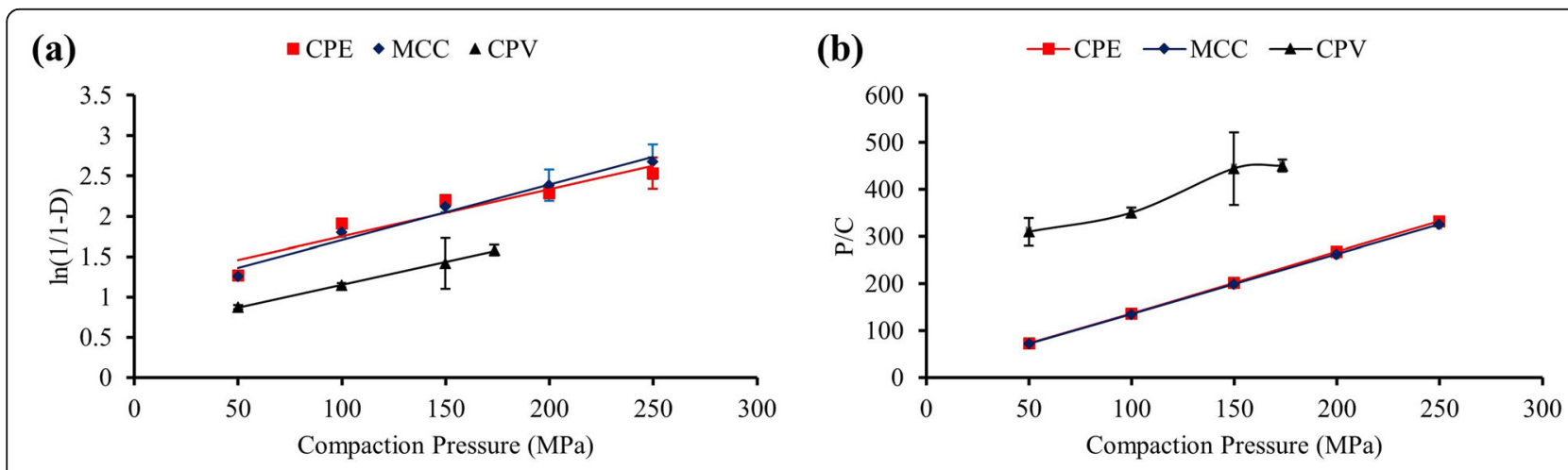

Fig. 1 a Heckel plot. b Kawakita plot 
Table 2 Heckel and Kawakita parameters for MCC, CPE, and CPV

\begin{tabular}{|c|c|c|c|c|c|c|c|}
\hline \multirow[b]{2}{*}{ Materials } & \multicolumn{4}{|l|}{ Heckel } & \multicolumn{3}{|c|}{ Kawakita } \\
\hline & $P_{Y}(\mathrm{MPa})$ & $D_{A}$ & $D_{0}$ & $D_{B}$ & $a$ & $b$ & $P_{\mathrm{K}}$ \\
\hline CPE & 172.41 & 0.69 & 0.23 & 0.46 & 0.77 & 0.17 & 5.74 \\
\hline MCC & 144.93 & 0.64 & 0.22 & 0.42 & 0.79 & 0.16 & 6.28 \\
\hline CPV & 178.57 & 0.44 & 0.49 & -0.05 & 0.80 & 0.01 & 193.88 \\
\hline
\end{tabular}

The compactibility plot displayed in Fig. 2b illustrates the effect of porosity on tensile strength of compacts produced. The plot shows that the tensile strength of compacts increased with decreasing porosity. The compactibility profile of all three materials was ranked in the following order: MCC > CPE > CPV. At all levels of porosity, the compacts of MCC returned higher tensile strength values compared to those of CPE and CPV.

The tabletability plot presented in Fig. 2c shows the effect of compaction pressure on tensile strength of compacts produced with all three materials. Tensile strength of compacts increased with increase in compaction pressure. At all pressures evaluated, the tensile strength of $\mathrm{MCC}$ compacts were consistently higher than those of $\mathrm{CPE}$ and $\mathrm{CPV}$. The tabletability profile of the three materials were thus ranked in the following order: $\mathrm{MCC}>\mathrm{CPE}>\mathrm{CPV}$.

\section{LSR}

The sensitivity of MCC to SSF was $45 \%$ as against $59 \%$ for CPE while the sensitivity of MCC to MST was $79 \%$ compared to $63 \%$ for CPE. MCC was found to be less sensitive to SSF compared to CPE and more sensitive to MST compared to CPE. Overall, both materials were more sensitive to the action of MST compared to SSF because the values obtained for SSF were much lower compared to those of MST.

\section{Dilution potential}

Figure 3 is a graphical representation of the outcome of dilution potential studies. Figure 3a shows that the tensile strength of PCM tablets formulated with either MCC or CPE as DC excipient decreased as the proportion of drug in the formulation increased. About $80 \%$ of MCC was required to produce tablets having a tensile strength of $2 \mathrm{MPa}$ in comparison to about 96\% of CPE that was required to produce tablets of the same tensile strength. This implies that MCC had a higher dilution potential compared to $\mathrm{CPE}$ with respect to PCM as model drug.

In the case of MTZ as model drug (Fig. 3b), the plot shows that tensile strength of tablets also decreased with increase in the proportion of drug in the formulation. Comparing the two excipients, $40 \%$ of MCC was required to produce tablets of $2 \mathrm{MPa}$ compared to $56 \%$ with CPE. This implies that MCC has a higher dilution potential compared to CPE.

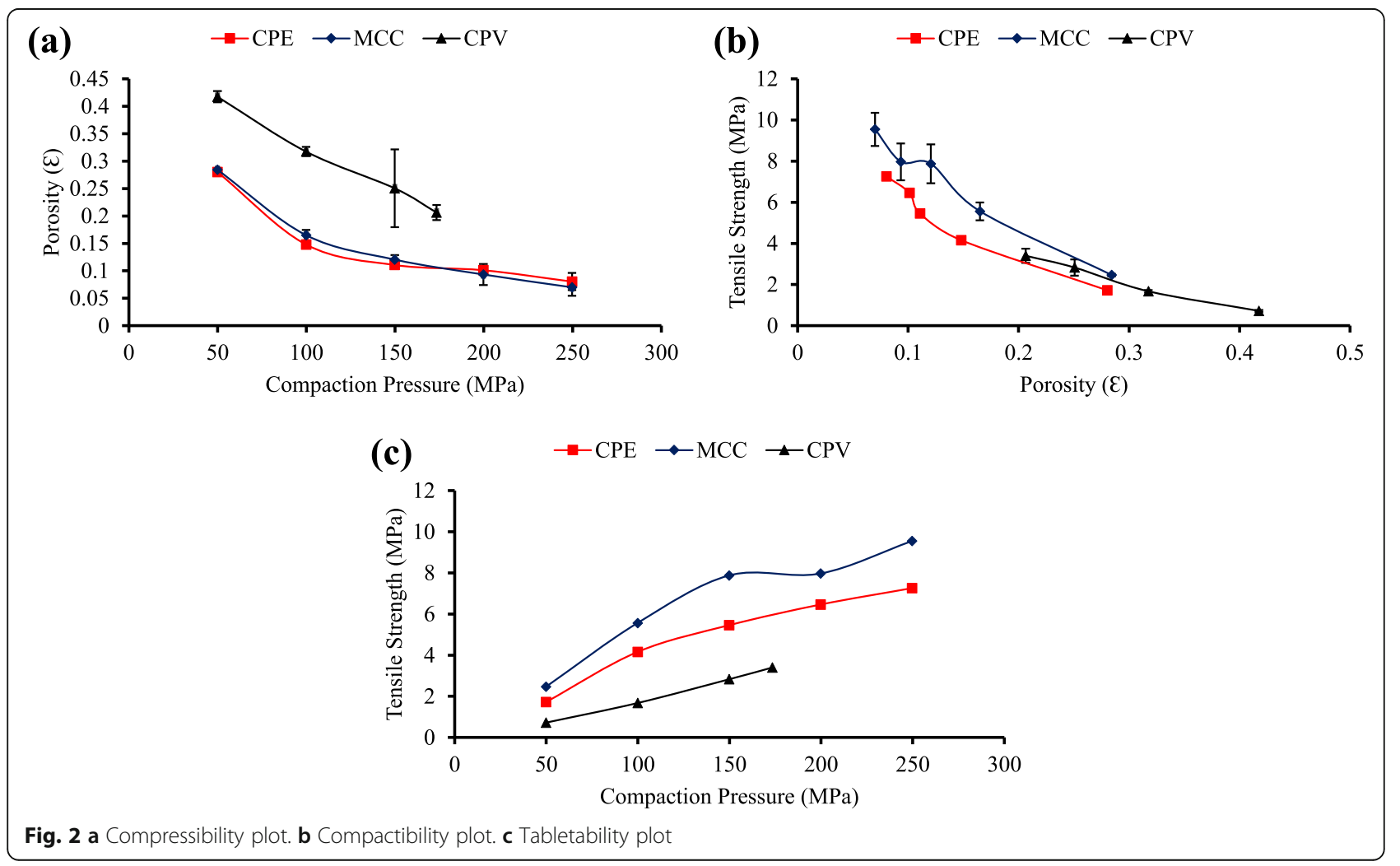



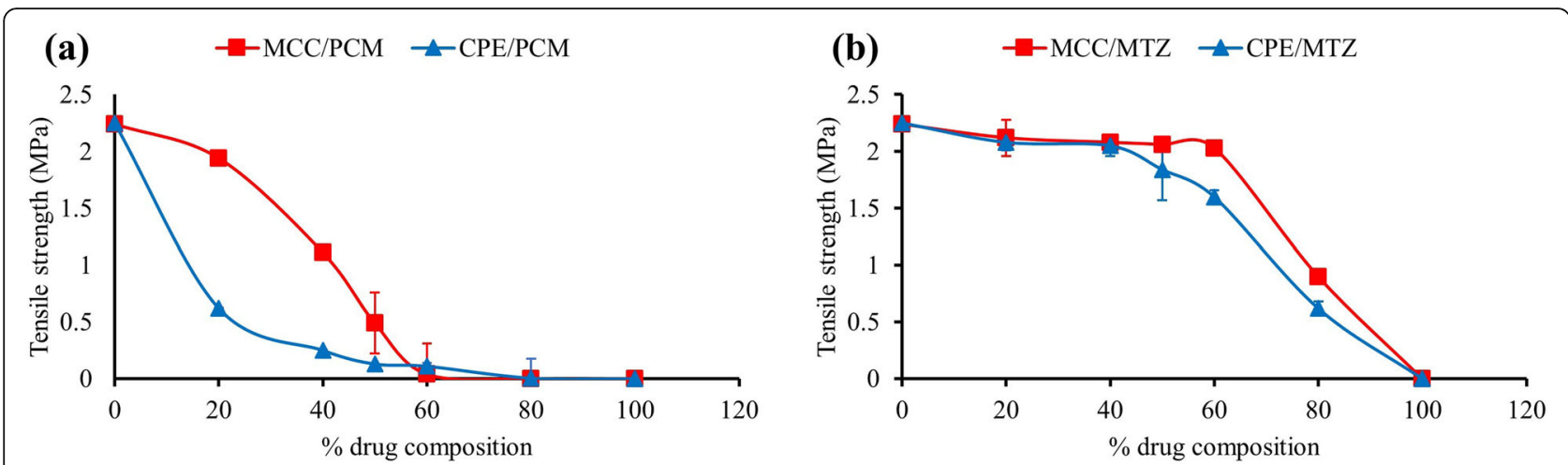

Fig. 3 Dilution potential plot of MCC and CPE using a PCM and $\mathbf{b}$ MTZ as model drugs

\section{Tablet properties}

The tableting properties of formulations I-IV are summarized in Table 3. The mean weight of tablets ranged from 491 to $497 \mathrm{mg}$ with formulations I and IV having the least tablet mean weight. Drug content of metronidazole varied from 86.72 to $106.47 \%$ with formulations III and I having minimum and maximum drug content, respectively. Tablet thickness showed that values ranged from 3.83 to $3.90 \mathrm{~mm}$. The tensile strength values obtained for the formulations were ranked in the following order: III > II > I > IV, where formulations containing PME and PSV as DC excipient returned the highest and lowest mean tensile strength values, respectively. The friability values obtained were consistent with the results obtained for tensile strength and all the formulations passed the friability test by not exceeding $1 \%$ except for formulation IV (PSV) that produced weak tablets having a friability $>1 \%$. The time taken for disintegration of tablets across the formulations ranged from 1.33 to $26.88 \mathrm{~min}$, with PSV and MCC yielding the minimum and maximum values of disintegration time, respectively.

The amount of drug released (\%) with time was represented in Fig. 4 as a dissolution plot. The time taken to release $80 \%$ of metronidazole was ranked in the following order: PSV < CPE < PME < MCC. The extent of drug release was highest with CPE, followed by PSV and PME and then MCC. All the formulations passed the dissolution test based on the USP requirement that $70 \%$ of the drug should be released in $45 \mathrm{~min}$.

\section{Discussion \\ Compaction studies}

As evidenced by Heckel analysis, compaction behavior of CPE was characterized by a lower degree of plastic deformation compared to MCC. This may have been caused by the introduction of CPV, a brittle material, into the particle structure of MCC during co-processing thereby increasing its hardness and making it more resistant to plastic deformation. Hence, a higher yield pressure was required to initiate deformation in CPE as compared to MCC. Reduction in plastic deformation of MCC by co-processing, however, lowered the compressibility and compactibility as seen in CPE (Fig. 2) and by extension the tabletability profile of CPE (Fig. 2). Due to a reduction in compressibility and compactibility, tablets of lower tensile strength were obtained with CPE characterized by some degree of porosity relatively higher than that of MCC. This led to a rapid disintegration of tablets prepared with CPE as opposed to those of MCC whose disintegration time exceeded the requirement for immediate release tablets (Table 3). Hence, the disintegration functionality of MCC was modified by lowering its extent of plastic deformation which created a more porous structure that facilitated the rapid uptake of water due

Table 3 Tableting properties of formulations I-IV

\begin{tabular}{lllll}
\hline Parameters & I & II & III & IV \\
\hline Mean weight (mg) & $491 \pm 9.68$ & $497 \pm 9.23$ & $497 \pm 8.65$ & $491 \pm 6.41$ \\
Drug content (\%) & $106.47 \pm 13.34$ & $102.48 \pm 1.07$ & $86.72 \pm 9.22$ & $97.35 \pm 0.27$ \\
Thickness (mm) & $3.83 \pm 0.62$ & $3.90 \pm 0.08$ & $3.90 \pm 0.05$ & $3.85 \pm 0.03$ \\
Tensile strength (MPa) & $1.38 \pm 0.11$ & $1.45 \pm 0.08$ & $1.62 \pm 0.08$ & $0.82 \pm 0.04$ \\
Friability (\%) & $0.61 \pm 0.29$ & $0.61 \pm 0.29$ & $0.61 \pm 0.28$ & $1.43 \pm 0.29$ \\
Disintegration time (min) & $26.88 \pm 4.17$ & $11.48 \pm 3.08$ & $7.32 \pm 2.66$ & $1.33 \pm 0.19$ \\
\hline
\end{tabular}

I MCC as DC excipient, // CPE as DC excipient, III PME as DC excipient, IV PSV as DC excipient 


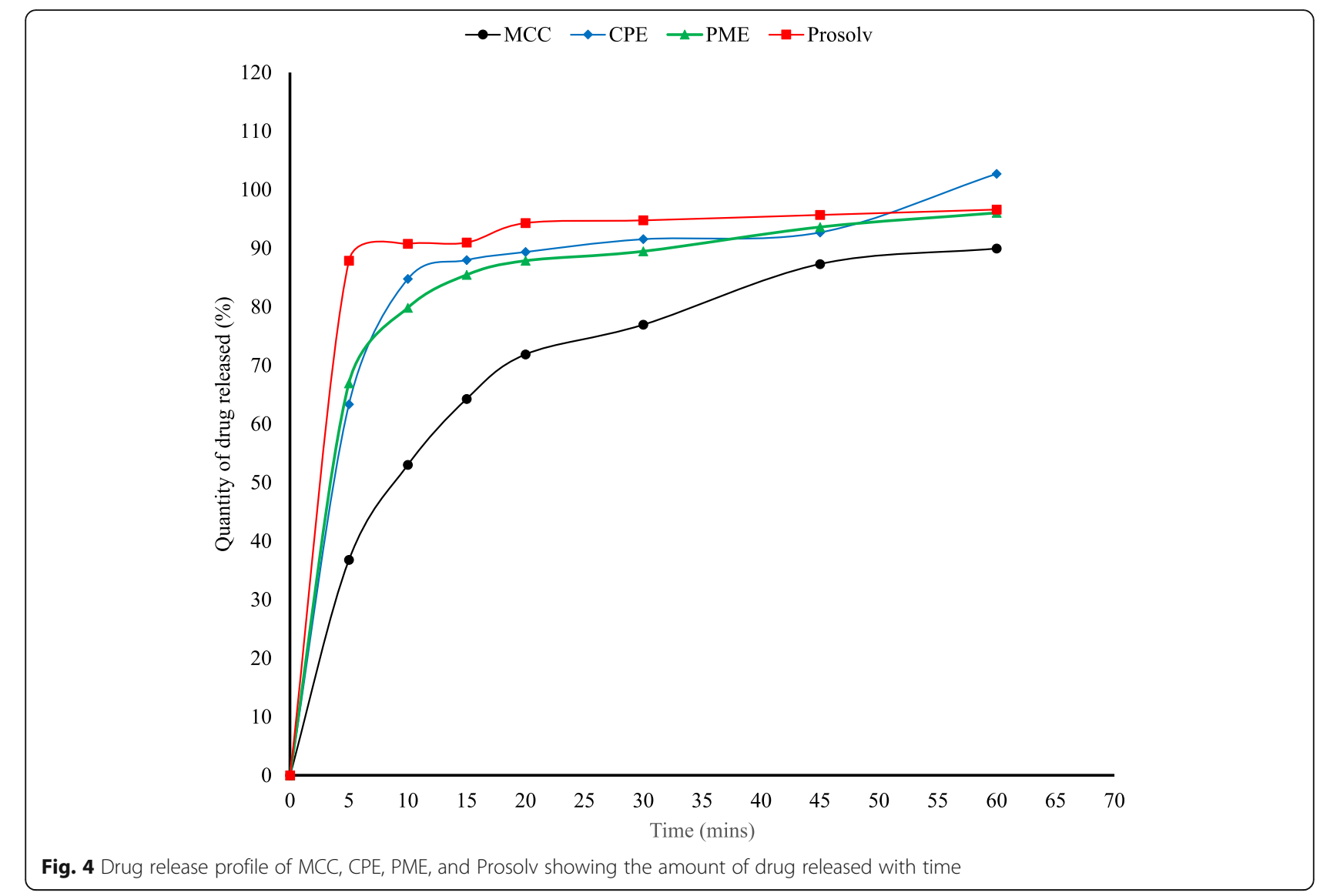

to the wicking properties of CPV leading to rapid disintegration of tablets. This agrees with the findings of Rojas and Kumar [15] who co-processed MCC II with colloidal silicon dioxide to yield an excipient with rapid disintegrating effect.

True density of CPE and MCC were similar, suggesting that the degree of molecular packing was not affected by co-processing. True density of a material has been able to relate the tabletability profile of a material to the interparticulate bonding strength [21]. However, the tabletability profile of MCC differed significantly from that of $\mathrm{CPE}$ owing to reduced interparticulate bonding caused by the presence of CPV in the particulate structure of MCC. Hence, similarity in molecular packing behavior (true density) does not necessarily translate to similar tabletability.

\section{LSR}

Lubrication is a tableting operation carried out prior to compression to lower interparticulate friction and prevent sticking of the tableting material to punch and die surfaces and to facilitate ejection of tablets after decompression [22, 23]. Lubricants exert their effect externally by coating the particle surfaces or forming a film layer at interparticulate surfaces [24].
This phenomenon interferes with interparticulate bonding and manifests as a reduction in tensile strength. Lubricant sensitivity testing is therefore carried out to quantify the degree of sensitivity of the tableting material to lubricant action. Depending on the mechanical properties, materials that are plastic deforming are more sensitive to lubricants compared to brittle materials [25].

Comparing the responses of $\mathrm{MCC}$ and $\mathrm{CPE}$ to lubricant action, both materials were generally more sensitive to MST compared to SSF possibly because MST has a greater degree of hydrophobicity [26, 27]. CPE was found to be more sensitive to the action of SSF when compared with MCC. This has been attributed to flowability of CPE that generates high shear forces during mixing leading to more efficient particle coating by the lubricant resulting in higher lubricant sensitivity [18]. However, MCC was found to be more sensitive to the action of MST compared to the response of CPE. Due to the smaller particle size of MCC, a relatively larger surface area of the particles was made available for coating by the lubricant giving rise to tablets of lower tensile strength after lubrication due to a reduction in interparticulate bonding [18]. This implies therefore that SSF will be a better candidate for lubrication compared to MST. 


\section{Dilution potential}

The ability of a DC excipient to incorporate a certain amount of active pharmaceutical ingredient (API) and form tablets of sufficient mechanical strength is described as the dilution potential of the excipient [28]. Dilution potential depends on the compaction behavior of the excipient and varies with API [28]. Plastic deforming materials tend to have better dilution potential compared to materials that deform by brittle fracture [18]. Dilution potential of MCC and CPE obtained with PCM were found to be significantly lower when compared to the dilution potential of MCC and CPE obtained with MTZ. This has been attributed to the brittleness and high elastic recovery exhibited by PCM upon compression [29-31]. On account of this, PCM, a high-dose drug, could not be compressed into tablets of convenient size by direct compression because of its low dilution potential. Hence, MTZ was selected as the drug of choice for the formulation of tablets by direct compression. Tablets designed to contain high-dose poorly compressible drugs are best prepared by wet granulation [32, 33]. A better dilution potential was obtained with MCC compared to CPE with respect to MTZ as model drug possibly because of the plastic deforming ability of MCC $[34,35]$. The plastic-deforming ability of MCC was lowered, however, when co-processed with CPV into CPE thereby reducing its capacity to take up more of the poorly compressible drug resulting in tablets of lower tensile strength due to a reduction in interparticulate bonding during compression. The dilution potential of MCC with respect to MTZ was therefore lowered as a result of co-processing to yield CPE.

\section{Tableting properties}

The quality of tablets obtained correlated with the compaction properties of the excipients used in tablet formulation. Tablets of relatively higher TS were obtained with MCC because of its excellent binding and tabletability profile associated with its tendency to undergo plastic deformation during compression [36]. The hardness of MCC tablets was reflected in the disintegration time which exceeded $15 \mathrm{~min}$ due to the inability of the disintegration medium to overcome the tightly bound tablet matrix created by extensive bonding area and strong interparticulate bonding occurring during tablet formation. The CPE tablets, however, disintegrated in less than $15 \mathrm{~min}$ owing to the porous structure generated as a result of its lowered tabletability profile. This ensured the rapid uptake of water that facilitated the breakup of the tablet during disintegration. Drug-release profile was consistent with the disintegration as tablets of CPE attained maximum drug release in rapid time compared to MCC tablets that released $<90 \%$ of the drug after $60 \mathrm{~min}$.

\section{Conclusion}

Co-processing of MCC and CPV yielded a composite material (CPE) that differed in its compaction and tableting behavior. The compaction behavior of $\mathrm{CPE}$ showed a material with a lesser degree of plasticity and tabletability when compared to MCC giving rise to tablets that disintegrated within $15 \mathrm{~min}$. Hence, the tableting properties of disintegration and drug release were enhanced by reason of co-processing. This study confirms the suitability of particle engineering techniques like co-processing in developing novel excipients with improved performance pharmaceutically.

\section{Abbreviations}

API: Active Pharmaceutical Ingredient; ANOVA: Analysis of variance; CPE: Coprocessed excipient; CPV: Crospovidone; CTC: Compressibility-tabletabilitycompactibility; DC: Direct compression; DT: Disintegration time; LSR: Lubricant sensitivity ratio; MCC: Microcrystalline cellulose; MST: Magnesium stearate; MTZ: Metronidazole; PCM: Paracetamol; PME: Physical mixture of excipients; PSV: Prosolv ${ }^{\oplus}$; SSF: Sodium stearyl fumarate; TS: Tensile strength; USP: United States Pharmacopoeia

\section{Acknowledgements}

The authors acknowledge JRS Pharma, Germany, and Evonik Industries, Germany, for the gift samples of excipients provided for the study.

\section{Authors' contributions}

FH collected the data and prepared the first draft of the manuscript. YEA designed the study, interpreted some of the results, and made critical revisions to the entire manuscript. CO collected and analyzed data for compaction studies. ARO and MG supervised the study and reviewed the manuscript. All the authors read and approved the final manuscript.

\section{Funding}

No external funding was received for this study. The resources used for the study were provided by the authors.

\section{Availability of data and materials}

The datasets used and/or analyzed during the current study are available from the corresponding author on reasonable request.

Ethics approval and consent to participate

Not applicable

Consent for publication

Not applicable

\section{Competing interests}

The authors declare that they have no competing interests.

\section{Author details}

'Department of Pharmaceutics and Industrial Pharmacy, Faculty of Pharmaceutical Sciences, Ahmadu Bello University, Zaria, Nigeria. ${ }^{2}$ Gamlen Tableting Ltd, London, UK

Received: 14 April 2020 Accepted: 7 July 2020

Published online: 17 July 2020

References

1. Wang S, Li J, Lin X, Feng Y, Kou X, Babu S et al (2015) Novel coprocessed excipients composed of lactose, HPMC, and PVPP for tableting and its application. Int J Pharm 486(1):370-379

2. Goyanes A, Martínez-Pacheco R (2015) New co-processed MCC-based excipient for fast release of low solubility drugs from pellets prepared by extrusion-spheronization. Drug Dev Ind Pharm 41(3):362-368

3. Apeji YE, Oyi AR, Isah AB, Allagh TS, Modi SR (2018) Bansal AK (2018) development and optimization of a starch-based co-processed excipient for direct compression using mixture design. AAPS PharmSciTech 19(2):866-880 
4. Assaf SM, Khanfar MS, Farhan AB, Said I, Badwan R, Ali A (2019) Preparation and characterization of co-processed starch/MCC/chitin hydrophilic polymers onto magnesium silicate. Pharm Dev Technol 24(6):761-774

5. Dong QQ, Zhou MM, Lin X, Shen L, Feng Y (2018) Differences in fundamental and functional properties of HPMC co-processed fillers prepared by fluid-bed coating and spray drying. Eur J Pharm Sci 119:147-158

6. Rojas J, Buckner I, Kumar V (2012) Co-processed excipients with enhanced direct compression functionality for improved tableting performance. Drug Dev Ind Pharm 38(10):1159-1170

7. Osamura T, Takeuchi Y, Onodera R, Kitamura M, Takahashi Y, Tahara K et al (2016) Characterization of tableting properties measured with a multifunctional compaction instrument for several pharmaceutical excipients and actual tablet formulations. Int J Pharm 510:195-202

8. Ghori MU, Conway B (2016) Powder compaction: compression properties of cellulose ethers. Br J Pharmacol 1:19-29

9. Chattoraj S, Sun CC (2018) Crystal and particle engineering strategies for improving powder compression and flow properties to enable continuous tablet manufacturing by direct compression. J Pharm Sci 107(4):968-974

10. Osei-Yeboah F, Chang S, Sun CC (2016) A critical examination of the phenomenon of bonding area - bonding strength interplay in powder tableting. Pharm Res 33:1126-1132

11. Goyanes A, Souto C, Martínez-Pacheco R (2011) Co-processed MCCEudragit ${ }^{\oplus}$ E excipients for extrusion-Spheronization. Eur J Pharm Biopharm 79:658-663

12. Olayemi O, Oyi A, Allagh T (2008) Comparative evaluation of maize, rice and wheat starch powders as pharmaceutical excipients. Nig J Pharm Sci 7(1): $131-138$

13. Hamid RAS, Al-Akayleh F, Shubair M, Rashid I, Al-Remawi M, Badwan A (2010) Evaluation of three chitin metal silicate co-precipitates as a potential multifunctional single excipient in tablet formulations. Mar Drugs 8(5):1699-1715

14. Allen L, Popovich N, Ansel H (2005) Powders and granules. In: Allen L, Popovich N, Ansel H (eds) Ansel's pharmaceutical dosage forms and drug delivery systems, 8th edn. Lippincott Williams \& Wilkins, New York, pp 186-203

15. Rojas J, Kumar $\vee$ (2011) Comparative evaluation of silicified microcrystalline cellulose II as a direct compression vehicle. Int J Pharm 416(1):120-128

16. Heckel RW (1961) Density-pressure relationships in powder compaction. Trans Metall Soc AIME 221:671-675

17. Kawakita K, Lüdde KH (1971) Some considerations on powder compression equations. Powder Technol 4(2):61-68

18. Almaya A, Aburub A (2008) Effect of particle size on compaction of materials with different deformation mechanisms with and without lubricants. AAPS PharmSciTech 9(2):414-418

19. British Pharmacopoeia (2013) Volume II. London, UK: Her Majesty's Stationery Office

20. Fell J, Newton J (1970) Determination of tablet strength by the diametralcompression test. J Pharm Sci 59(5):688-691

21. Khomane KS, More PK, Raghavendra G, Bansal AK (2013) Molecular understanding of the compaction behavior of indomethacin polymorphs. Mol Pharm 10(2):631-639

22. Wang J, Wen H, Desai D (2010) Lubrication in tablet formulations. Eur J Pharm Biopharm 75(1):1-15

23. Paul S, Sun C (2017) Lubrication with magnesium stearate increases tablet brittleness. Powder Technol 309:126-132

24. Jonat S, Hasenzahl S, Gray A, Schmidt P (2005) Influence of compacted hydrophobic and hydrophilic colloidal silicon dioxide on tableting properties of pharmaceutical excipients. Drug Dev Ind Pharm 31(7):687-696

25. Patel S, Kaushal AM, Bansal AK (2006) Compression physics in the formulation development of tablets. Crit Rev Ther Drug Carrier Syst 23(1):1-65

26. Perrault M, Bertrand F, Chaouki J (2011) An experimental investigation of the effect of the amount of lubricant on tablet properties. Drug Dev Ind Pharm 37(2):234-242

27. Morin G, Briens L (2013) The effect of lubricants on powder flowability for pharmaceutical application. AAPS PharmSciTech 14(3):1158-1168

28. Rojas J, Aristizabal J, Henao M (2013) Screening of several excipients for direct compression of tablets: a new perspective based on functional properties. J Basic Appl Pharm Sci 34(1):17-23

29. Roberts RJ, Rowe RC (1987) Brittle/ductile behaviour in pharmaceutical materials used in tabletting. Int J Pharm 36(2-3):205-209

30. Joiris E, Di Martino P, Berneron C, Guyot-Hermann A, Guyot J (1998) Compression behavior of orthorhombic paracetamol. Pharm Res 15(7):1122-1130
31. Persson A-S, Ahmed H, Velaga S, Alderborn G (2018) Powder compression properties of paracetamol, paracetamol hydrochloride, and paracetamol cocrystals and coformers. J Pharm Sci 107(7):1920-1927

32. Szumilo M, Belniak P, Swiader K, Holody E, Poleszak E (2017) Assessment of physical properties of granules with paracetamol and caffeine. Saudi Pharm J 25(6):900-905

33. Osamura T, Takeuchi Y, Onodera R, Kitamura M, Takahashi Y, Tahara K et al (2018) Formulation design of granules prepared by wet granulation method using a multi-functional single-punch tablet press to avoid tableting failures. Asian J Pharm Sci 13(2):113-119

34. Khomane KS, Bansal AK (2013) Yield strength of microcrystalline cellulose: experimental evidence by dielectric spectroscopy. Int J Pharm 455(1-2):1-4

35. Ilić I, Govedarica B, Šibanc R, Dreu R, Srčič S (2013) Deformation properties of pharmaceutical excipients determined using an in-die and out-die method. Int J Pharm 446(1):6-15

36. Thoorens G, Krier F, Leclercq B, Carlin B, Evrard B (2014) Microcrystalline cellulose, a direct compression binder in a quality by design environment a review. Int J Pharm 473:64-72

\section{Publisher's Note}

Springer Nature remains neutral with regard to jurisdictional claims in published maps and institutional affiliations.

\section{Submit your manuscript to a SpringerOpen ${ }^{\circ}$ journal and benefit from:}

- Convenient online submission

- Rigorous peer review

- Open access: articles freely available online

High visibility within the field

- Retaining the copyright to your article

Submit your next manuscript at $>$ springeropen.com 